OPEN ACCESS

Edited by:

Yi Guo,

University of Florida, United States

Reviewed by:

David Candon,

Nottingham Trent University,

United Kingdom

Dongyu Zhang,

University of Florida, United States

*Correspondence:

Edmond Pui Hang Choi

h0714919@connect.hku.hk

Specialty section:

This article was submitted to Life-Course Epidemiology and Social

Inequalities in Health,

a section of the journal

Frontiers in Public Health

Received: 16 May 2021

Accepted: 26 July 2021

Published: 24 August 2021

Citation:

Wu C, Choi EPH and Chau PH (2021) The Holistic Health Status of Chinese

Homosexual and Bisexual Adults: A

Scoping Review.

Front. Public Health 9:710575.

doi: 10.3389/fpubh.2021.710575

\section{The Holistic Health Status of Chinese Homosexual and Bisexual Adults: A Scoping Review}

\author{
Chanchan Wu, Edmond Pui Hang Choi* and Pui Hing Chau \\ School of Nursing, LKS Faculty of Medicine, The University of Hong Kong, Hong Kong, China
}

Background: Same-sex marriage is currently not legalized in China, despite the considerably large number of homosexual and bisexual Chinese populations. At the same time, their holistic health status remains unclear. This is the first scoping review conducted to comprehensively examine all the available literature and map existing evidence on the holistic health of homosexual and bisexual Chinese.

Methods: This scoping review used the framework of Arksey and O'Malley and followed the Preferred Reporting Items for Systematic Review and Meta-Analysis extension for scoping reviews (PRISMA-ScR). A comprehensive search strategy was carried out across 20 English (EN) and Chinese (both traditional and simplified) electronic databases from January 1, 2001, to May 31, 2020. Two reviewers conducted the reference screening and study selection independently and consulted a third senior reviewer whenever a consensus must be achieved. Data extraction was conducted using a structured data form based on the Cochrane template, after which a narrative synthesis of the findings was performed.

Results: A total of 2,879 references were included in the final analysis, with 2,478 research articles, 167 reviews, and 234 theses. Regarding the study populations, the vast majority of studies centered on men only (96.46\%), especially men who have sex with men (MSM). Only $1.32 \%$ of the studies targeted female sexual minorities. The geographical distribution of all research sites was uneven, with most of them being conducted in mainland China (95.96\%), followed by Hong Kong (2.05\%), Taiwan (2.02\%), and Macau (0.06\%). Regarding the specific study focus in terms of the health domain, around half of the studies (45.93\%) focused on sexual health only, and an additional quarter of the studies (24.15\%) investigated both sexual health and social well-being. Meanwhile, the studies focusing on mental health only accounted for approximately $15 \%$ of the total.

Conclusions: This scoping review revealed that previous research focused more on male than female sexual minorities, on disease-centered surveys than person-centered interventions, and investigations on negative health conditions than positive 
health promotion. Therefore, investigations centered on the female sexual minorities and corresponding person-centered interventions are highly needed.

Review Registration: The protocol of this review has been registered within Open Science Framework (https://osf.io/82r7z) on April 27, 2020.

Keywords: bisexual, Chinese, health, homosexual, men who have men with men

\section{INTRODUCTION}

Homosexuality and bisexuality have long existed worldwide, but the recognition of same-sex marriage in many countries has only gradually occurred in recent years. In comparison, under the heavy influence of Confucianism, it has always been a traditional obligation of Chinese adults to bring offspring to the family. Thus, homosexuality is widely rejected by the Chinese and is considered not only a threat to the family but also a threat to society. For nearly 20 years (1979-1997), sex between men was considered illegal and criminalized as "hooliganism" (sodomy) in China until it was eliminated in 1997 (1). In 2001, homosexuality was no longer classified as a pathology under the Chinese Classification of Mental Disorders (2), marking a historical turning point in the progress of homosexuality in China. Despite such developments, in contemporary China, the mainland government still recognizes neither legal same-sex marriage nor civil unions, and the situations in Hong Kong and Macau are similar. In contrast, same-sex marriage has been legalized in Taiwan since 2019, even though the law was enacted outside the Civil Code (3). In general, homosexual and bisexual Chinese from the above Cross-Straits Four-Regions have experienced similar cultural and policy backgrounds in the past two decades. Thus, research on this population is of historical significance in such an era.

Compared to some Western countries where homosexuals could either cohabit or enter legal same-sex marriages when available (4), most Chinese homosexuals can only choose to either stay single or develop hidden relationships "in the closet," and even fewer bisexual Chinese choose to disclose their sexual orientation (5). In recent decades, as research on these populations has gradually increased, some widely used behavioral concepts have been proposed by researchers to describe similar population groups regardless of their sexual identity (6-8), namely, men who have sex with men (MSM) and women

\footnotetext{
Abbreviations: WHO, World Health Organization; MSM, Men/Males who have Sex with Men/Males; WSW, Women who have Sex with Women; MSMW, Men who have Sex with both Men and Women; HIV, Human Immunodeficiency Virus; AIDS, Acquired Immune Deficiency Syndrome; STI, Sexually Transmitted Infections; JBI, Joanna Briggs Institute; PRISMA, Preferred Reporting Items for Systematic Reviews and Meta-Analyses statement; PRISMA-ScR, Preferred Reporting Items for Systematic Review and Meta-Analysis Extension for Scoping Reviews; PRISMA-P, Preferred Reporting Items for Systematic Reviews and Metaanalysis Protocols; PCC, Population Concept Context; MeSH, Medical Subject Headings; CMeSH, Chinese translation of Medical Subject Headings; CDC, Center for Disease Control and prevention; MU, Medical University; EN, English; CN, Chinese; SC, Simplified Chinese; TC, Traditional Chinese; NGO, NonGovernmental Organization; LGBTQ, Lesbian, Gay, Bisexual, Transgender or Queer people; GDP, Gross Domestic Product; CNY, Chinese Yuan.
}

who have sex with women (WSW). MSM/WSW populations may not only be involved in homosexual behaviors but also in bisexual behaviors. For instance, approximately $40 \%$ of MSM acknowledged being men who have sex with both men and women (MSMW) according to a national Chinese survey (9), while more than a quarter of the MSM claimed their sexual orientation to be bisexual (10). These indicate that research should not only focus on gays and lesbians from the perspective of sexual orientation but also on MSM and WSW from the perspective of sexual behavior.

According to the widely used definition of "health" introduced by the WHO, "Health is a state of complete physical, mental and social well-being and not merely the absence of disease or infirmity" (11). This definition explains the concept of "holistic health," which is a broad conceptualization of health that encompasses various dimensions, including complete physical health, mental health, and social well-being. Notably, sexual health is the most prevalent health domain in studies targeting homosexual or bisexual Chinese. Specifically, such research has always focused on certain diseases, such as AIDS and the related topic of HIV prevention, or other Sexually Transmitted Infections (STI) and unsafe sexual behaviors. Specifically, the overall national prevalence of HIV among MSM was 5.7\% from 2001 to 2018 (12), while that for syphilis for the same period was $11.8 \%$ (13). Thus far, only a few studies on Chinese WSW have been conducted compared to studies on MSM. According to the only domestic study investigating 224 Beijing WSW, $15.8 \%$ of this population were infected with gonorrhea though no HIV-positive cases were detected (14). Furthermore, about half of the WSW reported bleeding during or after sex, and many of them reported that they had experienced engaging in different kinds of high-risk sexual behaviors (15). All of these findings indicate that their worrying sexual health concerns may require further attention.

Although sexual minorities in China still face many significant psychosocial difficulties that are yet to be addressed, the most common of which is long-standing social discrimination or stigma based on sexual orientation (16), there are relatively a few studies on mental health and social well-being in this population compared to their counterparts in Western countries. In particular, both lesbians and gays in China reported feeling stressed and helpless in the face of expectations from society and their parents $(17,18)$. Moreover, both gay and bisexual Chinese men reported having suffered internalized homophobia $(19,20)$, which was found to be positively correlated with loneliness and negatively correlated with lower self-evaluation (19). At the same time, most psychosocial studies targeting sexual minorities were carried out in MSM populations from a behavioral perspective, with both qualitative and quantitative studies indicating that 
MSM often experienced homosexual stigma $(21,22)$ and HIVrelated stigma (23). Furthermore, MSM in China reported significantly higher levels of internalized homophobia compared with those from outside China (24), with a mean score of 2.04 vs. 1.77, as measured by the 4-point Likert Internalized Homophobia Scale. Chinese MSM also reported experiencing a high prevalence of other mental health issues, such as loneliness (35.5\%) (25), moderate-to-severe symptoms of depression (26.8-50.9\%) (2527 ), and anxiety $(26.0-36.4 \%)(26,27)$. Even worse are the high rates of suicide ideation and suicidal behavior. A study reported that the specific suicide ideation rates were $31 \%$ among gay and bisexual men in Taiwan (28) and 26\% among MSM in nine cities of mainland China (29). Meanwhile, over 12\% of MSM actually attempted suicide (29), which is several times higher than that of the normal adult men (30). All these indicate that many Chinese homosexuals and bisexuals suffer from poor mental health, which could lead to self-loathing and negative effects on their self-identity (31). These mental health issues could also have further negative effects on their sexual health and/or social well-being (32).

Currently, in China, there are no census data on either the homosexual or bisexual population. This has caused concerns, given that China is the most populous country in the world, which means that the number of sexual minorities could be proportionately higher compared with those in other countries. Furthermore, with the wide use of the Internet and increasing social tolerance, sexual minority groups are no longer as hidden as before; hence, their social and health needs should be understood and addressed. Nevertheless, prevailing public attitudes toward homosexuality remain negative. For example, over half $(58.4 \%)$ of the MSM in Hong Kong reported experiencing public discrimination (33), similar to the situation in mainland China (34).

To date, there have been studies on homosexual and bisexual Chinese, especially within the MSM population. These studies mainly centered on STI-/HIV-related prevalence or prevention attempts $(12,35-43)$, or focused on human rights and the legalization of same-sex marriage, as conducted in the fields of sociology, anthropology, law, and psychology (44-46). However, other aspects of health and well-being have yet to be fully investigated. At the same time, there are even fewer studies on female sexual minorities compared with male ones (45), thus highlighting the need for further academic attention.

In summary, the current health-related research targeting Chinese homosexual and bisexual adults seem to be unbalanced from the perspective of the gender population and health domains, indicating the essential need for further scientific review evidence. So far, there is no systematically reviewed evidence available or ongoing review either in English (EN) or Chinese on the holistic health of homosexual and bisexual people within the Chinese context. In addition, the current evidence is difficult to summarize due to variations in the types of studies and the less precisely defined subjects and research variables.

In relation to the above, a scoping review, which is a type of systematic review, can be used to comprehensively map the known information about a topic based on the available information and then identify the potential gaps in the literature, thus facilitating an assessment of the state of knowledge about the specific topic (47-50). In 2018, the Preferred Reporting Items for Systematic Reviews and Meta-Analyses Statement was extended to Scoping Reviews (PRISMA-ScR) (51). Therefore, the current review was conducted as a systematic scoping review, following the PRISMA-ScR checklist (Supplementary Material 1). This review aims to comprehensively examine the literature to explore the breadth of current knowledge relating to the holistic health of homosexual and bisexual Chinese, identify potential knowledge gaps, and then inform future in-depth research on how to improve the health of this particular population.

\section{METHODS}

This study used the scoping review framework developed by Arksey and O'Malley (2005) (47) and further updated as recommended by the Joanna Briggs Institute (JBI) (50). This review was also conducted in accordance with a priori protocol currently under review (52), including five stages: 1) identification of the review questions, 2) identification of relevant studies, 3) study selection, 4) data extraction, and 5) summarization and reporting of the results.

\section{Stage 1: Identification of the Review Questions}

The "PCC" mnemonic, representing Population-ConceptContext, is recommended by the JBI (53) as a guide to construct clear research questions for a scoping review. Correspondingly, in this review, "Population" refers to all Chinese homosexual and bisexual adults living in mainland China, Hong Kong, Macau, or Taiwan. Chinese sexual minorities who were born or living abroad were excluded due to policy and cultural differences. Furthermore, in this review, "Concept" refers to holistic health, a broad conceptualization of health defined by the WHO (11) that encompasses varied dimensions of health, including the complete physical, mental, and social well-being of an individual. This review, therefore, targeted all these health-related aspects. Finally, "Context" refers to the locations of study settings. Thus, following the overarching review question: "What is the holistic health status of Chinese homosexual and bisexual adults?" some detailed review questions are as follows: 1) "What health-related variables have been investigated about homosexual and bisexual Chinese?" 2) "What types of research have been conducted and which disciplines were most involved in carrying out studies targeting this population?" and 3) "What are the differences among the sample populations in terms of sexual orientation (between homosexuals and bisexuals) and gender (between male and female minorities)?”

\section{Stage 2: Identification of Relevant Studies and Search Strategy}

The eligibility criteria for this scoping review using the PCC framework are shown in the a priori protocol. In addition to homosexual and bisexual people from the perspective of sexual orientation, MSM/MSMW and WSW groups were also included in terms of behavioral categories. Regarding the concept of holistic health, after reviewing health-related definitions (54-58), this review included both negative and positive variables related 
to mental health, physical (sexual) health, and social well-being. In terms of context, this review included studies conducted in all regions of China, including mainland cities, Hong Kong, Macau, and Taiwan. Regarding the inclusion criteria of the study types, all original studies using qualitative, quantitative, or mixed methods, reviews and published dissertations were included. Meanwhile, study protocols or blogs, book chapters, conference abstracts, research letters, editorial notes or commentaries were excluded.

For a comprehensive literature search, research articles, reviews, and theses published in 2001 or later were searched. This is because homosexuality has no longer been regarded as a mental illness in China since 2001 (2). All relevant databases in both EN and CN languages related to health care, psychology, and social science were searched. Specifically, 20 databases were searched, including $12 \mathrm{EN}$ language databases (PubMed, Web of Science, CINAHL Plus, ScienceDirect, Social Work Abstracts, APA PsycInfo, etc.), four Simplified Chinese (SC) databases (China National Knowledge Infrastructure-CNKI, China Biological Medicine Database-SinoMed, etc.), and four traditional Chinese (TC) databases (Index to Taiwan periodical literature system, National Digital Library of Theses, Dissertation in Taiwan, etc.).

The search strategy for this review was adapted from the Peer Review of Electronic Search Strategies (PRESS) Evidence-Based Checklist (59). Handsearching was also used as a supplementary method, although unpublished documents were excluded from this review due to limited resources. Pilot searching was conducted in both EN (PubMed) and CN (SinoMed) language databases before the formal search, with the aim of identifying all relevant keywords or subject headings before finalizing the search strategy. The Medical Subject Headings (MeSH terms) and corresponding Chinese translation $\mathrm{MeSH}$ terms (CMeSH terms) are summarized in the Supplemental Material 2. The final search of the above mentioned databases was conducted throughout May 2020 and updated on May 31, 2020. Some updated studies were further reviewed on a monthly basis by checking the available email alerts (Supplementary Material 3).

\section{Stage 3: Study Selection}

After searching, the identified records were exported to and managed by EndNote X9 (for EN and TC literature) and NoteExpress (for SC literature). Both software programs could automatically identify duplicate records. Then, two reviewers independently performed the study selection, which included title screening, abstract screening, and full-text screening according to the JBI guidelines $(51,53)$. Specifically, the title and abstract screening were carried out simultaneously referring to the PCC criterion, and the number of excluded references in each step was recorded and compared. In case of inconsistencies, the two reviewers discussed until data consistency was achieved. Afterward, the full texts of all potentially eligible references were retrieved for further screening, and disagreements on the study selection were resolved by a discussion between the two main reviewers and consultation with a third senior researcher. Finally, those references that were excluded during full-text screening were recorded following specific exclusion reasons, in line with the PCC framework (Supplementary Material 4).

\section{Stage 4: Data Extraction}

Initially, a data extraction template was developed based on the Cochrane Data Extraction Template (60), after confirming all essential variables and key information to extract. Then, after conducting the pilot extraction using both qualitative and quantitative eligible studies, a revised and detailed version of the data extraction form was used. The data extraction was also conducted independently by two reviewers with regular discussion, and then continuously updated in an iterative manner. Specifically, the data extracted included specific details about the "Reference Characteristics," "Study Characteristics," and also "PCC-related Information," including authors and affiliations, year of publication, study design, population and sample size, study settings, health domains, and corresponding findings.

\section{Stage 5: Summarization and Reporting of the Results}

All retrieved information from the data extraction form was documented in Microsoft Excel, and narrative synthesis was used. The quantitative findings were descriptively summarized in the form of tables using frequencies and percentages. Next, the summarization of qualitative evidence including the collaboration network and co-word analysis was conducted via social network analysis by UCINET (61) and then visualized using the NetDraw program (62). The critical appraisal process is not necessary for a scoping review $(48,49)$, and it is also not feasible to evaluate the quality of each included reference (Supplementary Material 5). Nevertheless, this review tried to perform a quality evaluation of the journals in which all the included articles were published (Supplementary Material 6).

\section{RESULTS}

The final database search from January 1, 2001, to May 31, 2020 , yielded a total of 14,811 references. After removing 4,227 duplicates, 10,584 references remained for further screening. Specifically, 5,655 were excluded after title screening, and 1,328 were excluded after abstract screening as they did not meet the PCC eligibility criteria. Of the 3,601 remaining records for full-text screening, 727 were excluded due to specific reasons (Supplementary Material 4). Finally, a total of 2,879 references incorporating an additional five references obtained through the manual search were included in the final analysis (Supplementary Material 5), including 2,645 articles and 234 theses. From the perspective of the publishing language, there were $708 \mathrm{EN}$ references, 2,151 SC records, and 20 TC records. The study screening and selection were conducted following the PRISMA flow diagram (63). The detailed process and specific results are presented in Figure 1.

\section{Time Trends of Publications and Corresponding Studies}

Among all the 2,879 included references, the overall number of publications gradually increased and then stabilized in the 


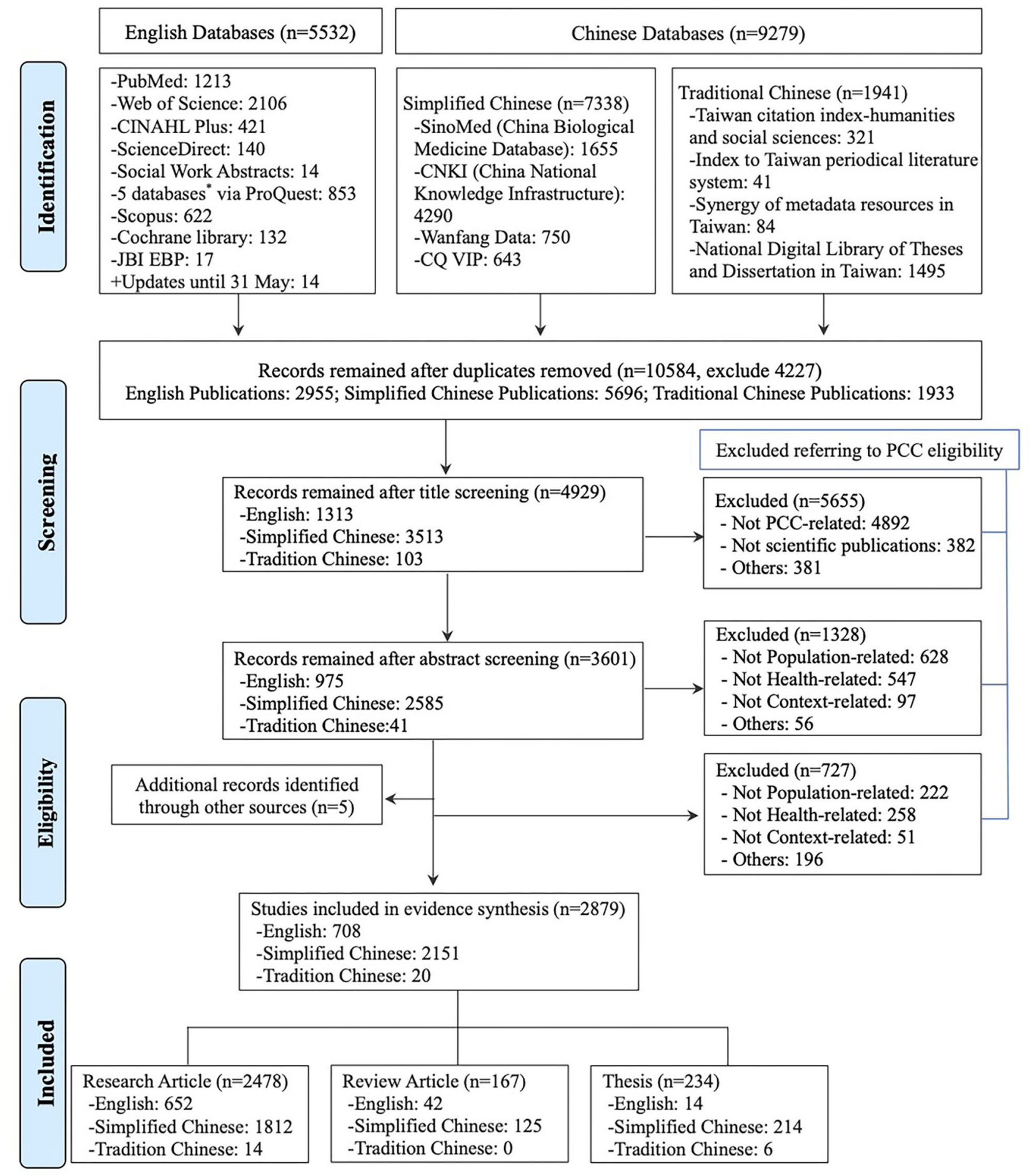

FIGURE 1 | Search results and study selection process referring to Preferred Reporting Items for Systematic Review and Meta-Analysis (PRISMA). *: ProQuest searching of the 5 databases: ProQuest Dissertations \& Theses A\&l; ProQuest Dissertations \& Theses Global; APA Psyclnfo; Sociological Abstracts; Social Services Abstracts.

past two decades (blue line in Figure 2). As this study only included references published before May 2020, the data in 2020 were dropped from both Figures 2, 3, so as not to distract the trends. Regarding the trend in the number of studies started each year over time, it can be seen that the research conducted before 2010 increased year by year, while the following decade (2011-2019) showed a significant downward trend (orange line in Figure 2). Review articles first appeared 


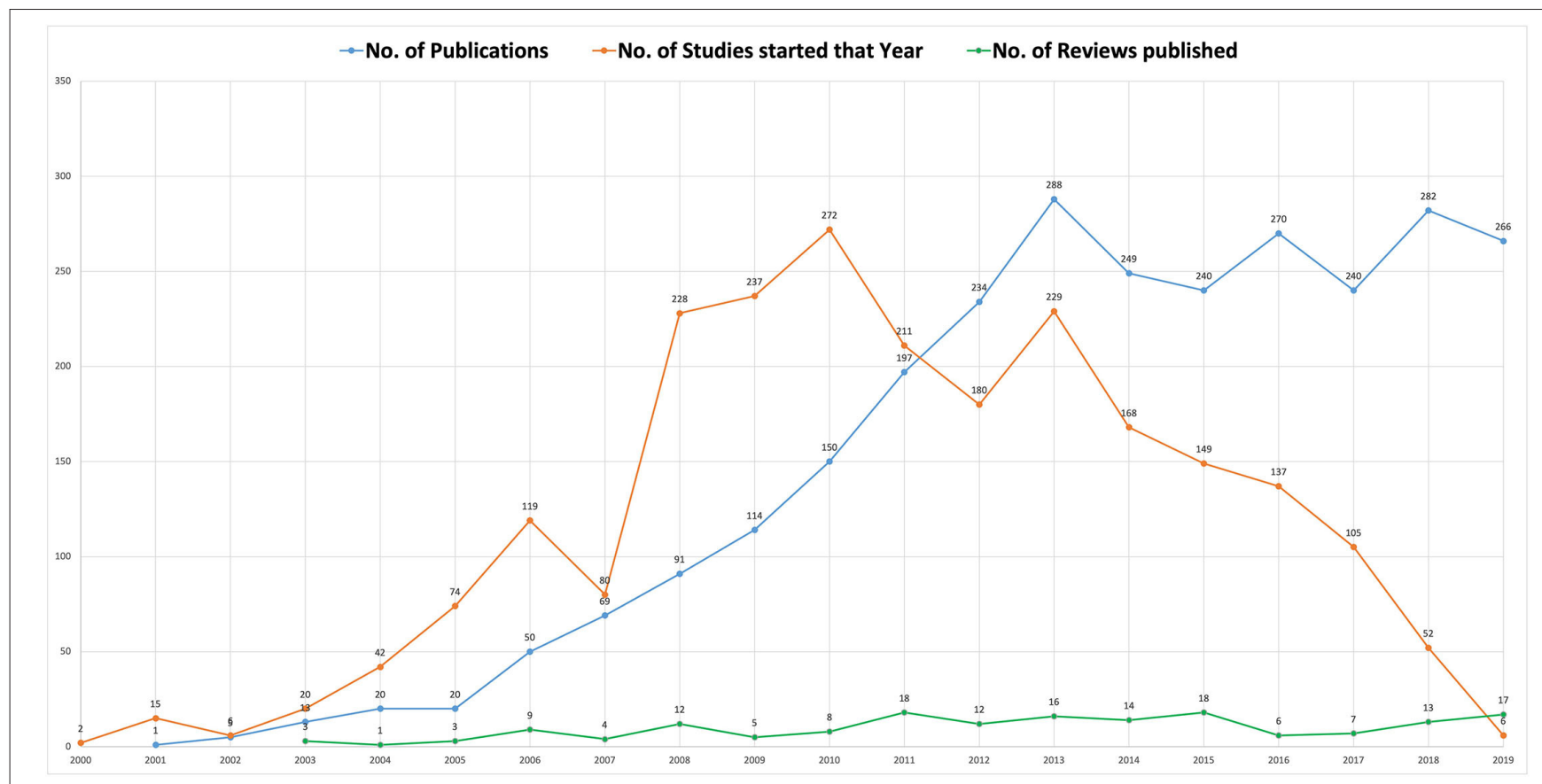

FIGURE 2 | Time trends of publications, corresponding studies, and reviews. Since this study only included references published before May 2020 , the data in 2020 was dropped as it would be distracting the trends.

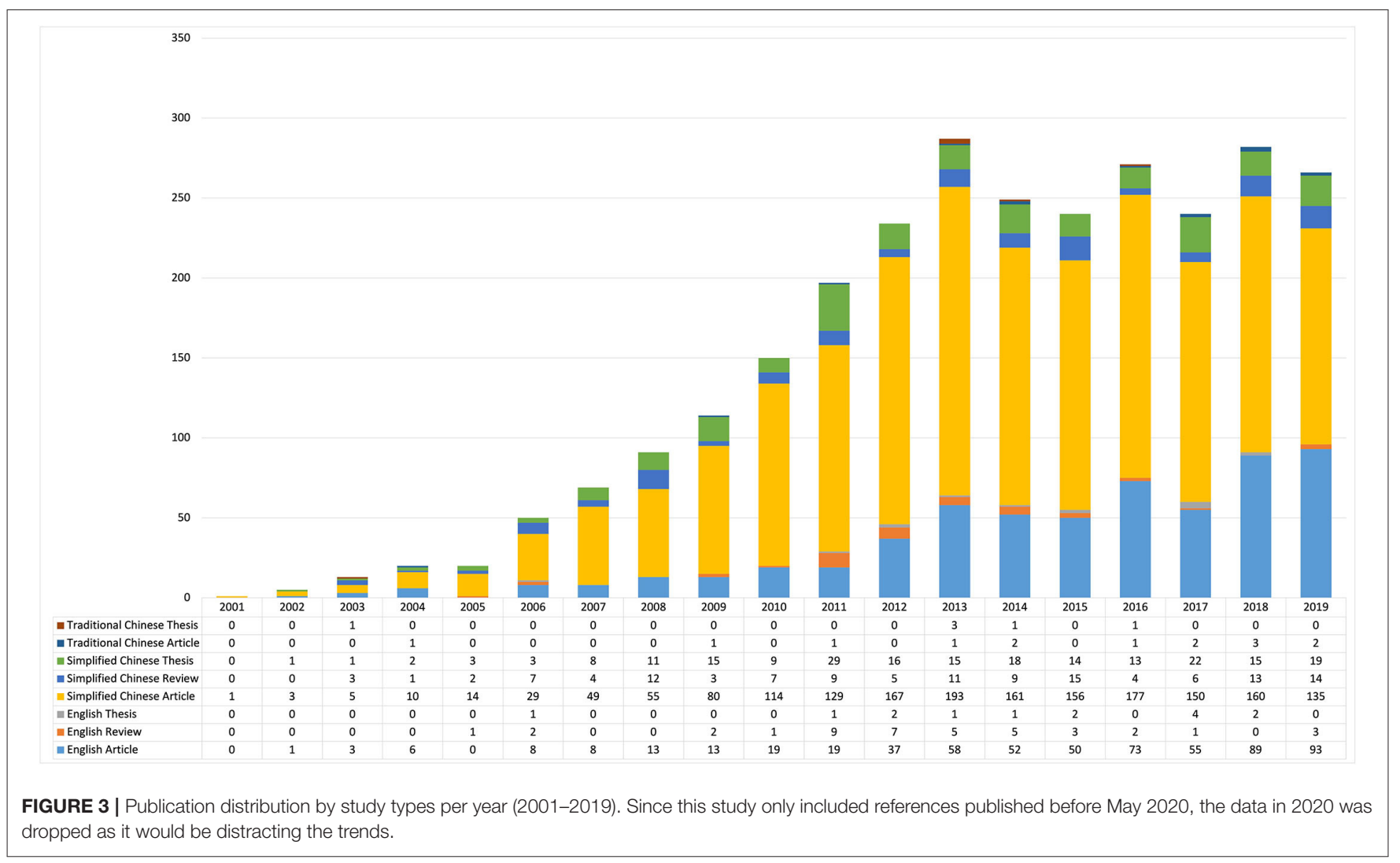


in 2003, and around 10 reviews were conducted every year thereafter without an obvious trend of increase or decrease (green line in Figure 2).

Among the 2,879 included publications, $74.71 \%(2,151)$ were written in SC and $86.07 \%(2,478)$ were research articles. Figure 3 shows the distribution of study types in both EN and CN publications. Among the 234 theses, some incorporated two or more independent studies (cross-sectional survey and following intervention study); thus a total of 276 identical studies were carried out.
Author Affiliations and Funding Information

Regarding the distribution of author affiliations, the majority of affiliations (89.41\%) were located in mainland China, of which more than half $(54.74 \%)$ were affiliated with the Center for Disease Control and Prevention (CDC), and around a third (33.53\%) were affiliated with universities, mainly medical universities (MUs). As for institutional cooperation, over half of the studies $(55.24 \%)$ were conducted by a single institution; and approximately one-third of the research (30.40\%) was carried out through domestic cooperation, which was more

TABLE 1 | Institutional characteristics of 2,645 articles and 234 theses.

\begin{tabular}{|c|c|c|c|}
\hline Article institutions $(n=2,645)$ & No. (\%) & Thesis institutions $(n=234)$ & No. (\%) \\
\hline First author affiliation & & Degree & \\
\hline CDC & $1,448(54.74)$ & Master thesis & $200(85.47)$ \\
\hline University & $887(33.53)$ & PhD thesis & $34(14.53)$ \\
\hline Hospital & $256(9.68)$ & Author affiliation & \\
\hline Scientific Institution & $29(1.10)$ & Mainland China & $214(91.45)$ \\
\hline Health authority & $10(0.38)$ & Hong Kong & $10(4.27)$ \\
\hline Others & $15(0.57)$ & Taiwan & $6(2.56)$ \\
\hline First author affiliation location & & Overseas & $4(1.71)$ \\
\hline Mainland China & $2365(89.41)$ & Universities & \\
\hline Overseas & $144(5.44)$ & 中国疾病预防控制中心(China CDC) & $28(11.97)$ \\
\hline Hong Kong & $85(3.21)$ & 安徽医科大学(Anhui MU) & $24(10.26)$ \\
\hline Taiwan & $48(1.81)$ & 重庆医科大学(Chongqing MU) & $15(6.41)$ \\
\hline Macau & $2(0.08)$ & 山东大学(Shandong University) & $11(4.70)$ \\
\hline Not available & $1(0.04)$ & The Chinese University of Hong Kong & $10(4.27)$ \\
\hline First author profession ${ }^{a}$ & & 第三军医大学(TMMU) & $9(3.85)$ \\
\hline Public health & $430(63.70)$ & 天津医科大学(Tianjin MU) & $9(3.85)$ \\
\hline Psychology & $43(6.37)$ & 河北医科大学(Hebei MU) & $8(3.42)$ \\
\hline Global health & $26(3.85)$ & 青岛大学(Qingdao University) & $8(3.42)$ \\
\hline Nursing & $18(2.67)$ & 吉林大学(Jilin University) & $7(2.99)$ \\
\hline Sociology & $18(2.67)$ & 昆明医科大学(Kunming MU) & $6(2.56)$ \\
\hline Medicine & $11(1.63)$ & 新疆医科大学(Xinjiang MU) & $6(2.56)$ \\
\hline Psychiatry & $10(1.48)$ & 中国医科大学(China MU) & $6(2.56)$ \\
\hline Not available & $15(2.22)$ & 山西医科大学(Shanxi MU) & $5(2.14)$ \\
\hline Others & $104(15.41)$ & Others & $82(35.04)$ \\
\hline If involved nursing profession & & Profession/Major & \\
\hline Yes & $92(3.48)$ & Epidemiology & $112(47.86)$ \\
\hline No & $2553(96.52)$ & Public health & $53(22.65)$ \\
\hline First author is nursing profession & & Social Medicine & $13(5.56)$ \\
\hline Yes & $55(2.08)$ & Psychology & $10(4.27)$ \\
\hline No & $2590(97.92)$ & Dermatology & $8(3.42)$ \\
\hline Institution cooperation & & Sociology & $6(2.56)$ \\
\hline International cooperation & $380(14.37)$ & Nursing & $4(1.71)$ \\
\hline Domestic cooperation & $804(30.40)$ & Maternal, Child and Adolescent Health & $4(1.71)$ \\
\hline Single institution & $1461(55.24)$ & Others & $24(10.25)$ \\
\hline Funding sources $^{b}$ & & Funding sources $^{b}$ & \\
\hline Not funded/ Not available & $1092(37.93)$ & Global Funding & $107(3.72)$ \\
\hline Mainland China & $1056(36.68)$ & Hong Kong & $53(1.84)$ \\
\hline China and foreign funding & $343(11.91)$ & Taiwan & $31(1.08)$ \\
\hline America & $130(4.52)$ & Funding from other organizations & $67(2.33)$ \\
\hline
\end{tabular}

${ }^{a}$ Among 675 studies published in English (EN) (652 research papers and 23 studies from 14 theses). ${ }^{b}$ Among all 2,879 publications. 
common in $\mathrm{CN}$ articles than in EN publications (29.38 vs. $1.02 \%$, respectively). In contrast, the proportion of international cooperation among authors in EN publications exceeded that in $\mathrm{CN}$ publications (12.40 vs. $1.97 \%$, respectively). Regarding the funding information, $36.68 \%(1,056 / 2,879), 1.84 \%$ (53), and $1.08 \%$ (31) of studies obtained funding from mainland China, Hong Kong, and Taiwan, respectively, while over one-third (37.93\%) of studies were not funded. Furthermore, around $23 \%$ of the studies were funded by foreign organizations or global sources (Table 1), thereby revealing the global nature of these related studies.

\section{Characteristics of the Included Reviews}

Review articles accounted for the smallest proportion $(167 / 2,645$, $6.31 \%$ ) of all articles, among which $25.15 \%$ (42/167) were published in EN and 74.85\% (125/167) were published in SC. Most of the reviews centered only on the male population, especially MSM (151, 90.42\%), while only four reviews focused on female sexual minorities (Table 2). These findings indicate the insufficient attention given to this population, thus highlighting the need for further research in this group. Notably, there was just one scoping review among all the included reviews, which summarized only the HIV prevalence and corresponding prevention intervention programs for MSM and transgender populations (64). Overall, the included reviews mostly focused on sexual health $(86.83 \%)$, such as the incidence or prevalence of HIV/STI and related treatment. In comparison, less attention was given to mental health (7.19\%) and social well-being $(2.40 \%)$.

\section{Characteristics of the Included Studies}

There are 2,754 studies in all the included publications, including 2,478 research articles (1,812 SC, 14 TC, and $652 \mathrm{EN}$ publications) and 276 studies from 234 theses. The majority of the studies $(2,677,97.20 \%)$ used the originally collected data, while the remaining ones were conducted as secondary analyses using previous data. Of all the original studies, nearly half $(1,324$, 48.46\%) had sample sizes between 101 and 500; and 23.53\% had sample sizes larger than 1,000, most of which involved series of cross-sectional surveys. Given that there were a certain number of published $\mathrm{CN}$ studies with unclear descriptions of the methodologies used, the detailed characteristics of the study design and sampling methods used data from the 675 published EN studies (652 research articles and 23 studies from 14 theses). Specifically, most of the studies $(75.41 \%)$ were conducted as cross-sectional investigations, followed by qualitative studies (54, $8.00 \%$ ); less than $1 \%$ were mixed-method studies (Table 3). Around a quarter of the studies used multiple sampling methods, followed by the Internet- and venue-based sampling methods.

\section{Population Information}

Among all the 2,879 publications, the vast majority of the research, whether original studies or reviews, focused on MSM $(2,667,92.64 \%)$. Specifically, in the $675 \mathrm{EN}$ publications with detailed population descriptions, most average ages ranged between 20 and 35 years. There was just one study that targeted bisexual people only (65), while over 40 studies involved homosexuals only. In addition, in all studies that indicated
TABLE 2 | Characteristics of the included reviews.

\begin{tabular}{|c|c|c|c|c|}
\hline Target population & English reviews & $\begin{array}{l}\text { Chinese } \\
\text { reviews }\end{array}$ & Total & $\%$ \\
\hline Male only & 41 & 113 & 154 & $92.22 \%$ \\
\hline MSM & 40 & 111 & 151 & $90.42 \%$ \\
\hline Gay & / & 2 & 2 & $1.20 \%$ \\
\hline MSMW & 1 & / & 1 & $0.60 \%$ \\
\hline Female only & 1 & 3 & 4 & $2.40 \%$ \\
\hline Lesbian & 1 & 1 & 2 & $1.20 \%$ \\
\hline WSW & / & 2 & 2 & $1.20 \%$ \\
\hline Both gender & 0 & 9 & 9 & $5.39 \%$ \\
\hline Gay \& Lesbian & / & 6 & 6 & $3.59 \%$ \\
\hline MSM \& WSW & / & 3 & 3 & $1.80 \%$ \\
\hline \multicolumn{5}{|l|}{ Clinical people or not } \\
\hline HIV-infected & 1 & 4 & 5 & $2.99 \%$ \\
\hline Non patient & 41 & 121 & 162 & $97.01 \%$ \\
\hline \multicolumn{5}{|l|}{ Review type } \\
\hline General literature review & 11 & 111 & 122 & $73.05 \%$ \\
\hline Systematic Review (SR) & 6 & 2 & 8 & $4.79 \%$ \\
\hline SR and Meta-analysis & 24 & 12 & 36 & $21.56 \%$ \\
\hline Scoping review & 1 & & 1 & $0.60 \%$ \\
\hline \multicolumn{5}{|l|}{ Review focus } \\
\hline Sexual health & 40 & 105 & 145 & $86.83 \%$ \\
\hline Mental health & 1 & 11 & 12 & $7.19 \%$ \\
\hline Social well-being & 1 & 3 & 4 & $2.40 \%$ \\
\hline Overall review or others & / & 6 & 6 & $3.59 \%$ \\
\hline
\end{tabular}

specific sexual orientation, the proportion of homosexuals was greatly higher than that of bisexuals (Table 4). Nearly two-thirds of the studies collected data on the marital status of the sample populations (around 10-30\% were married). Thus, the marital and living conditions of homosexuals and bisexuals, along with their spouses, are worthy of further exploration.

\section{Context Information}

Among all 2,712 research references (2,478 research articles and 234 theses), 2,704 provided clear setting information, including 3,310 study sites (both single and multiple sites), although the geographical distribution of all study sites was uneven. Specifically, when analyzing all study sites from publications in both languages, $95.96 \%$ of the studies were conducted in mainland China, followed by Hong Kong (2.05\%), and Taiwan $(2.02 \%)$; meanwhile, only two nationwide studies $(66,67)$ involved Macau $(0.06 \%)$, and no original single-site study was conducted in Macau. Furthermore, when analyzing study sites in EN publications, similarly, the majority of studies $(83.41 \%)$ were conducted in mainland China, followed by Hong Kong (8.89\%) and Taiwan (6.52\%). However, when considering the geographical area or population size, the results showed that more studies were conducted per unit area or population in Hong Kong, compared with Taiwan, the mainland, and Macau (in descending order). In all the research conducted in mainland China, study sites were mostly located in the east $(841,25.41 \%)$ and southwest $(742,22.42 \%)$. Three places 
TABLE 3 | Study and sampling characteristics of included EN studies.

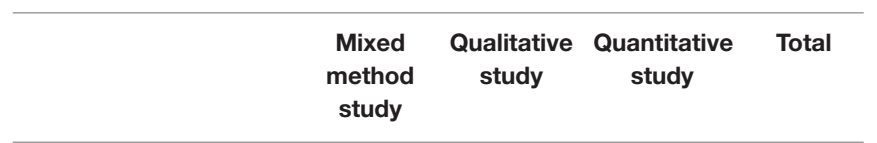

\begin{tabular}{|c|c|c|c|c|}
\hline \multicolumn{5}{|l|}{ Sampling method } \\
\hline Multiple methods & $1(0.15)$ & $12(1.78)$ & $160(23.7)$ & $173(25.63)$ \\
\hline Internet-based sampling & $1(0.15)$ & $3(0.44)$ & $112(16.59)$ & $116(17.19)$ \\
\hline Venue-based sampling & / & $5(0.74)$ & $97(14.37)$ & $102(15.11)$ \\
\hline Convenience sampling & / & $4(0.59)$ & $82(12.15)$ & $86(12.74)$ \\
\hline Snowball sampling & $2(0.30)$ & $9(1.33)$ & 65 (9.63) & $76(11.26)$ \\
\hline $\begin{array}{l}\text { Respondent Driven } \\
\text { Sampling }\end{array}$ & $2(0.30)$ & / & $62(9.19)$ & $64(9.48)$ \\
\hline Purposive sampling & / & $18(2.67)$ & $6(0.89)$ & $24(3.56)$ \\
\hline Not available & / & / & $13(1.93)$ & $13(1.93)$ \\
\hline Others & / & $3(0.44)$ & $7(1.04)$ & $10(1.48)$ \\
\hline Random sampling & / & I & $9(1.33)$ & $9(1.33)$ \\
\hline Time-Location Sampling & / & / & $2(0.30)$ & $2(0.30)$ \\
\hline \multicolumn{5}{|l|}{ Modality of recruitment } \\
\hline Offline & $3(0.44)$ & $41(6.07)$ & $294(43.56)$ & $338(50.07)$ \\
\hline Mixed & $2(0.30)$ & $8(1.19)$ & $172(25.48)$ & $182(26.96)$ \\
\hline Online & $1(0.15)$ & $5(0.74)$ & $135(20.00)$ & $141(20.89)$ \\
\hline Not clear & / & / & $14(2.07)$ & $14(2.07)$ \\
\hline \multicolumn{5}{|l|}{ Sample size } \\
\hline $1-50$ & / & $49(7.26)$ & $1(0.15)$ & $50(7.41)$ \\
\hline $51-100$ & / & $5(0.74)$ & $14(2.07)$ & $19(2.81)$ \\
\hline $101-200$ & $1(0.15)$ & / & $39(5.78)$ & $40(5.93)$ \\
\hline $201-300$ & $1(0.15)$ & / & $68(10.07)$ & $69(10.22)$ \\
\hline $301-400$ & / & / & 87 (12.89) & $87(12.89)$ \\
\hline $401-500$ & / & / & 97 (14.37) & $97(14.37)$ \\
\hline $501-600$ & / & / & $67(9.93)$ & $67(9.93)$ \\
\hline $601-700$ & / & / & $29(4.30)$ & $29(4.30)$ \\
\hline $701-800$ & / & / & $15(2.22)$ & $15(2.22)$ \\
\hline $801-900$ & / & / & $20(2.96)$ & $20(2.96)$ \\
\hline $901-1000$ & $2(0.30)$ & / & $14(2.07)$ & $16(2.37)$ \\
\hline$>1000$ & $2(0.30)$ & / & $164(24.3)$ & $166(24.59)$ \\
\hline \multicolumn{5}{|l|}{ Data collection person } \\
\hline Researcher & $1(0.15)$ & $52(7.70)$ & $252(37.33)$ & $305(45.19)$ \\
\hline Participant & $1(0.15)$ & / & 259 (38.37) & $260(38.52)$ \\
\hline Researcher or Participants & $4(0.59)$ & $2(0.30)$ & $75(11.11)$ & $81(12.00)$ \\
\hline Not clear & / & / & $29(4.30)$ & $29(4.30)$ \\
\hline \multicolumn{5}{|l|}{ Data collection method } \\
\hline Questionnaires & $1(0.15)$ & $1(0.15)$ & $388(57.48)$ & $390(57.78)$ \\
\hline $\begin{array}{l}\text { Laboratory tests \& } \\
\text { questionnaire }\end{array}$ & / & / & $213(31.56)$ & $213(31.56)$ \\
\hline Interviews & / & $43(6.37)$ & $2(0.30)$ & $45(6.67)$ \\
\hline Laboratory tests & / & / & $10(1.48)$ & $10(1.48)$ \\
\hline Questionnaires \& interviews & $5(0.74)$ & / & / & $5(0.74)$ \\
\hline $\begin{array}{l}\text { Focus Group Discussion } \\
\text { (FGD) }\end{array}$ & / & $5(0.74)$ & / & $5(0.74)$ \\
\hline Interviews \& FGD & / & $4(0.59)$ & / & $4(0.59)$ \\
\hline $\begin{array}{l}\text { Others/ Multiple } \\
\text { approaches }\end{array}$ & $1(0.15)$ & $1(0.15)$ & $1(0.15)$ & $3(0.45)$ \\
\hline Total & $6(0.89)$ & 54 (8) & $615(91.11)$ & $675(100)$ \\
\hline
\end{tabular}

TABLE 4 | Population characteristics of all included references.

\begin{tabular}{|c|c|c|c|}
\hline $\begin{array}{l}\text { Population } \\
\text { characteristics }\end{array}$ & No. (\%) & Characteristics & No. (\%) \\
\hline Target population ${ }^{a}$ & & Gender $^{a}$ & \\
\hline MSM & 2,667 (92.64) & Male only & 2,777 (96.46) \\
\hline Gay & $66(2.29)$ & Both gender & $60(2.08)$ \\
\hline Gay \& Lesbian & $33(1.15)$ & Female only & $38(1.32)$ \\
\hline $\begin{array}{l}\text { Homosexual \& bisexual } \\
\text { Male }\end{array}$ & $28(0.97)$ & $\begin{array}{l}\text { Other (include } \\
\text { transgender) }\end{array}$ & $4(0.14)$ \\
\hline $\begin{array}{l}\text { General homosexual \& } \\
\text { bisexual }\end{array}$ & $21(0.73)$ & $\begin{array}{l}\text { Whether patients or } \\
\text { not }^{\mathrm{a}}\end{array}$ & \\
\hline Lesbian & $19(0.66)$ & Non patients & $2,626(91.21)$ \\
\hline WSW & $15(0.52)$ & HIV-infected people & $241(8.37)$ \\
\hline MSMW & $10(0.35)$ & Others (Syphilis) & $12(0.42)$ \\
\hline Bisexual Male & $6(0.21)$ & Orientation $^{\mathrm{b}}$ & \\
\hline MSM and WSW & $6(0.21)$ & All homosexual & $40(5.93)$ \\
\hline $\begin{array}{l}\text { Homosexual \& bisexual } \\
\text { Female }\end{array}$ & $4(0.14)$ & All bisexual & $1(0.15)$ \\
\hline Others (LGBTQ+) & $4(0.14)$ & Homosexual rate & \\
\hline Mean years of age ${ }^{b}$ & & $<40.0 \%$ & $9(1.34)$ \\
\hline$<20.0$ & $1(0.15)$ & $40.0-49.9 \%$ & $26(3.85)$ \\
\hline $20.0 \sim 29.9$ & $226(33.48)$ & $50.0-59.9 \%$ & $50(7.41)$ \\
\hline $30.0 \sim 39.9$ & $100(14.81)$ & $60.0-69.9 \%$ & $82(12.15)$ \\
\hline$\geq 40.0$ & $4(0.89)$ & $70.0-79.9 \%$ & $119(17.63)$ \\
\hline NA & $342(50.67)$ & $\geq 80.0 \%$ & $80(11.85)$ \\
\hline Marriage rate (ever) ${ }^{b}$ & & NA & 268 (39.70) \\
\hline $0-9.9 \%$ & $73(10.81)$ & Bisexual rate & \\
\hline $10.0-19.9 \%$ & $183(27.11)$ & $<20.0 \%$ & $82(12.15)$ \\
\hline $20.0-29.9 \%$ & $104(15.41)$ & $20.0-29.9 \%$ & $107(15.85)$ \\
\hline $30.0-39.9 \%$ & $47(6.96)$ & $30.0-39.9 \%$ & $48(7.11)$ \\
\hline $40.0-59.9 \%$ & $30(4.44)$ & $40.0-49.9 \%$ & $21(3.11)$ \\
\hline $60.0-88.6 \%$ & $12(1.78)$ & $50.0-59.9 \%$ & $6(0.89)$ \\
\hline All married & $3(0.44)$ & $\geq 60.0 \%$ & $2(0.30)$ \\
\hline NA & 223 (33.04) & NA & 368 (54.52) \\
\hline
\end{tabular}

${ }^{a}$ Data from all 2,879 publications; ${ }^{b}$ Data from 675 studies published in EN only.

that had the highest number of studies were Sichuan Province (383, 11.57\%), Guangdong Province (316, 9.55\%), and Beijing Municipality (286, 8.64\%).

In addition, this review attempted to provide an economic description of the study sites in terms of gross domestic product (GDP). The results showed that all study sites can be categorized into three groups, "Economically developed areas" [per capita GDP exceeding CNY $¥ 100,000$, Chinese Yuan (CNY)], "Economically moderate areas" (per capita GDP between CNY $¥ 50,000$ and CNY $¥ 100,000$ ), and "Economically underdeveloped areas” (per capita GDP less than CNY $¥ 50,000$ ). Most of the studies were conducted in economically moderate or developed areas ( 57.43 vs. $32.57 \%$, respectively), while only $10 \%$ were carried out in economically underdeveloped areas, indicating the insufficient attention given to relatively poor places. Regarding the specific study settings, over half of the studies (63.85\%) were conducted offline [usually in CDCs, some gay communities, or through non-governmental organizations 
TABLE 5 | Context characteristics of all included references.

\begin{tabular}{|c|c|c|c|}
\hline $\begin{array}{l}\text { Context } \\
\text { characteristics }\end{array}$ & No. (\%) & Context characteristics & No. (\%) \\
\hline $\begin{array}{l}\text { Single or } \\
\text { multi-sites }\end{array}$ & & Study conducted setting ${ }^{a}$ & \\
\hline Single site & $2,251(83.00)$ & Offline & \\
\hline Multi-sites & $453(16.70)$ & Offline-CDC & $92(13.63)$ \\
\hline Not clear & $8(0.29)$ & Offline-Clinic & $66(9.78)$ \\
\hline $\begin{array}{l}\text { Geographical } \\
\text { division of all } \\
\text { sites }^{b}\end{array}$ & & Offline-Gay community & $81(12.00)$ \\
\hline Hong Kong & $68(2.05)$ & Offline-NGO & $33(4.89)$ \\
\hline Taiwan & $67(2.02)$ & Offline-Not clear & $158(23.41)$ \\
\hline Macau & $2(0.06)$ & Offline-University & $1(0.15)$ \\
\hline Mainland & 3,173 (95.86) & Online & \\
\hline East China & $841(25.41)$ & Online-Application (App) & $5(0.74)$ \\
\hline Southwest China & 742 (22.42) & Online-Internet & $100(14.81)$ \\
\hline South China & $445(13.44)$ & Online-Internet \& App & $27(4.00)$ \\
\hline North China & $436(13.17)$ & Online-Not clear & $3(0.44)$ \\
\hline Central China & $269(8.13)$ & Online-Telephone & $10(1.48)$ \\
\hline Northeast China & $252(7.61)$ & Online \& Offline & $54(8.00)$ \\
\hline Northwest China & $188(5.68)$ & Not mentioned & $45(6.67)$ \\
\hline $\begin{array}{l}\text { Geographical } \\
\text { division of English } \\
\text { publications }^{\mathrm{a}}\end{array}$ & & $\begin{array}{l}\text { Site division according to } \\
\text { economic status }^{c}\end{array}$ & \\
\hline Mainland & $563(83.41)$ & Economically developed areas & $1,078(32.57)$ \\
\hline Hong Kong & $60(8.89)$ & Economically moderate areas & $1,901(57.43)$ \\
\hline Taiwan & $44(6.52)$ & Economically underdeveloped & $331(10.00)$ \\
\hline Multi-sites & $8(1.19)$ & areas & \\
\hline
\end{tabular}

aData from 675 studies published in EN only. ${ }^{b}$ Data from all studies mentioning the study sites (3,310 sites in total). 'According to the Gross Domestic Product (GDP) per capita, "Economically developed areas" include Hong Kong, Macau, Taiwan, Beijing, Shanghai, Jiangsu, Fujian, Tianjin, and Zhejiang; "Economically moderate areas" include Guangdong, Chongqing, Hubei, Shandong, Inner Mongolia, Shaanxi, Anhui, Hunan, Liaoning, Sichuan, Jiangxi, Henan, Hainan, Ningxia, Xinjiang, Xizang, Yunnan, Qinghai, Jilin, and Shanxi; and "Economically underdeveloped areas" include Hebei, Guizhou, Guangxi, Heilongjiang, and Gansu.

(NGOs)], while around one-fifth of the studies (14.81\%) were conducted online via Internet websites (Table 5).

\section{Concept Information}

Among all keywords that appeared in the included publications, "MSM" had the highest frequency as population variables in both $\mathrm{CN}$ and EN publications, followed by some sexual healthrelated concepts (e.g., HIV, STI, and sexual behaviors) and concepts related to mental health (e.g., stigma and depression), as shown in Supplementary Material 7. However, the concept of "social well-being" or other positive health-related concepts did not appear frequently. Co-word analysis was conducted to map the relationships among all keywords using UCINET and NetDraw (61), in which a higher number of co-occurrences indicated a closer relationship between the two keywords, as shown in Figure 4. The colors and lines were automatically generated after K-core analysis, specifically, the larger the number corresponding to the color, the higher the frequency of co-occurrence; the thicker the line, the stronger the degree of co-occurrence. Correspondingly, the results showed that "MSM" was the keyword with the highest frequency (1,908 times), co-occurring most frequently with other keywords. This was followed by "HIV" and "AIDS." In addition, HIV-/STI- and sexual health-related words were also high-frequency keywords. At the same time, keywords, such as "University students" appeared, indicating that young people were gaining increasing research attention. However, the frequency of the keyword "Lesbian" was very low, and that of "Bisexual" was even lower. Overall, male- and sexual health-related keywords appeared more frequently than female- and other health-related variables.

In addition, this review extracted the specific foci of 675 published EN studies, which had clear descriptions of the study variables they used. Among them, around half (45.93\%) focused on sexual health only, and an additional quarter (24.15\%) investigated both sexual health and social well-being. In comparison, the total number of studies focused on mental health accounted for only about $15 \%$, whether it was the only variable in the research or one of the variables used (Table 6). Although the number of studies conducted for different genders varied greatly (627 vs. 16), the comparison revealed that male-related research focused more on sexual health (HIV/STI), while female-related research was relatively more concerned with mental health $(25.00$ vs. 3.35\%). Furthermore, four studies investigated breast-related health among female sexual minorities (68-71), all of which were conducted in Taiwan.

This review also extracted all the health-related variables and corresponding measurement tools mentioned in the 675 studies published in EN. In comparison, less than a quarter of the studies clearly stated that they used validated scales $(19.48 \%)$ or selfdeveloped tools $(4.73 \%)$, most of which reported their reliability or validity. Specifically, the most studied variables were still sexual health-related, such as sexual behavior and HIV screening (Table 7). The word clouds (Supplementary Material 7) also showed comparisons of variables investigated among the 16 female-specific studies and 627 male-specific studies.

\section{DISCUSSION}

To the best of our knowledge, this is the first scoping review conducted to synthesize the holistic health of homosexual and bisexual populations in mainland China, Hong Kong, Macau, and Taiwan. So far, it is also the most comprehensive systematic scoping review, with the highest number of included literature published in both EN and CN. Specifically, this review included all scientific literature published from January 2001 to May 2020, since homosexuality was removed from the list of mental illnesses in China in 2001 (2). The trends of all publications showed that research on related minorities increased significantly year by year, reaching a peak in 2013, and then gradually stabilized in the following years with some fluctuations. However, when observing the trend of new studies carried out every year, the trend of a gradual decrease in research over the past decade (2011-2020) is evident, indicating that research attention on this population is gradually decreasing. Considering the reality that 


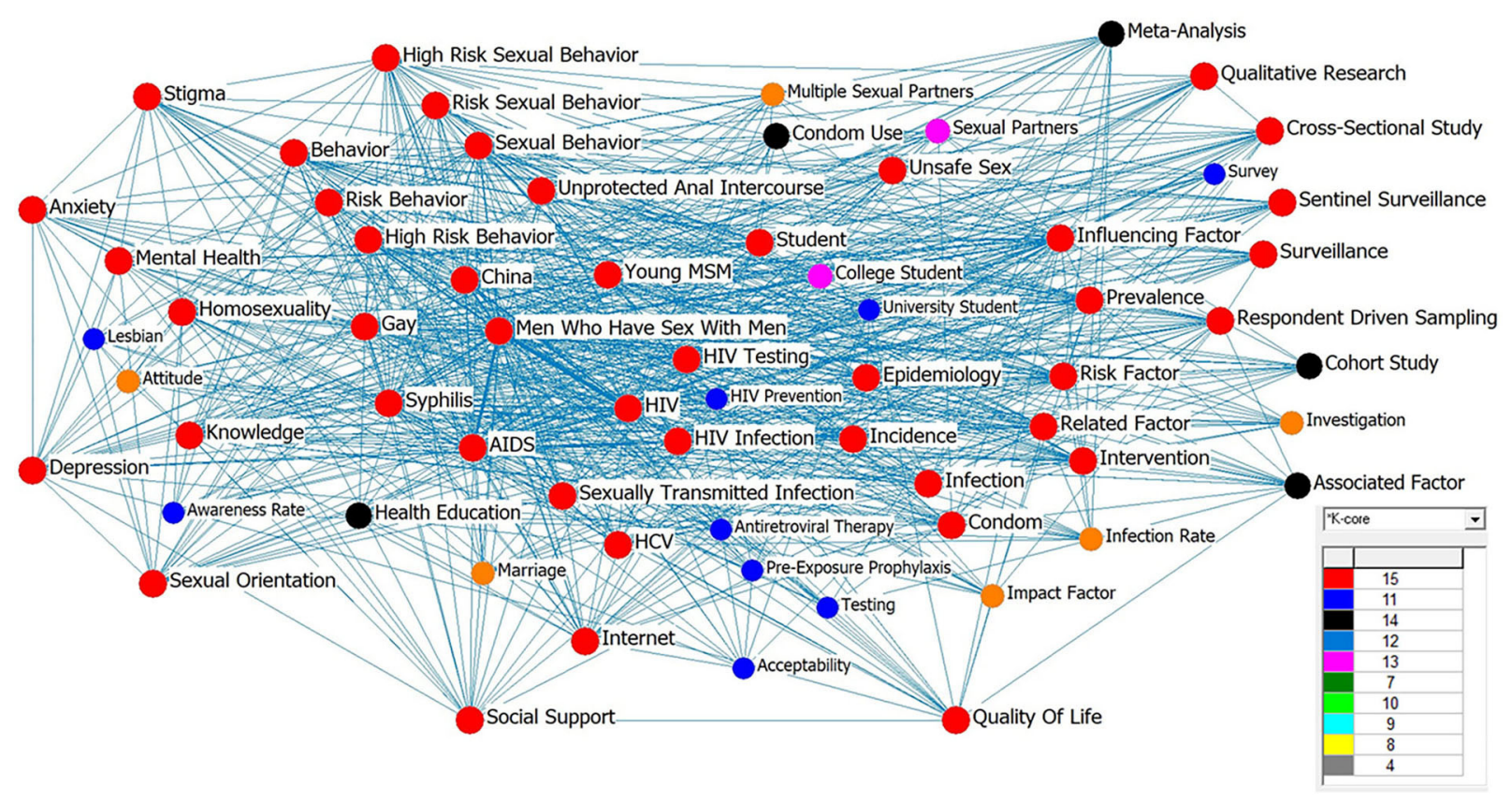

FIGURE 4 | Co-word analysis of all English (EN) keywords and translation of Chinese ones. The colors and lines were automatically generated after K-core analysis, specifically, the larger the number corresponding to the color, the higher the frequency of co-occurrence; the thicker the line, the stronger the degree of co-occurrence.

more and more sexual minorities are choosing to "come out" $(72,73)$, thus decreasing trend is a cause for concern and warrants further academic attention.

In response to the core review question in line with the PCC framework, this review found that there are far more studies on homosexuals than on bisexuals and other sexual minorities. In particular, the attention given to the male population was much higher than that to female groups ( 96.46 vs. $1.32 \%$, respectively), especially in the most extensive MSM-related publications (92.64\%). Regarding specific health-related concepts, there were far more studies on sexual health than investigations of mental health or social well-being (Table 7). In particular, the HIV/STI-centered research was more common, with the concerns of scholars gradually evolving from HIV/STI prevalence (41, $74-76)$, treatment $(77,78)$, and corresponding adherence (79, 80) toward various prevention approaches, including both professional-led $(81,82)$ and self-testing/self-care programs (8385). However, despite the prevalence of disease-centric research, less attention was paid to positive health concepts, such as sexual satisfaction, with only one survey conducted in the male group (86) while no relevant investigations for female minorities. All the above findings suggest that more research on female sexual minorities is needed in the future, whether research on mental health or the positive aspects of sexual health.

Specifically, there was an increased prevalence of HIV, syphilis, and gonorrhea among MSM $(12,87,88)$. Although HIV was not detected in the female population in the existing studies, other diseases were relatively common, such as gonorrhea, chlamydia, and bacterial vaginosis (14), all indicating a worrying trend in sexual health in these sexual minorities. In terms of mental
TABLE 6 | Study focus and gender differences in 675 studies published in EN.

\begin{tabular}{lcccc}
\hline Study focus & $\begin{array}{c}\text { Female } \\
\text { (\% in 16) }\end{array}$ & $\begin{array}{c}\text { Male } \\
\text { (\% in 627) }\end{array}$ & $\begin{array}{c}\text { Both } \\
\text { gender } \\
\text { (\% in 32) }\end{array}$ & $\begin{array}{c}\text { Total } \\
\text { (\% in 675) }\end{array}$ \\
\hline $\begin{array}{l}\text { Sexual health } \\
\begin{array}{l}\text { Sexual health, Social } \\
\text { well-being }\end{array}\end{array}$ & $2(12.50)$ & $307(48.96)$ & $1(3.13)$ & $310(45.93)$ \\
$\begin{array}{l}\text { Mental health, Social } \\
\text { well-being }\end{array}$ & $/$ & $160(25.52)$ & $2(6.25)$ & $163(24.15)$ \\
$\begin{array}{l}\text { Sexual health, Mental health } \\
\text { Social well-being }\end{array}$ & $3(18.75)$ & $36(5.74)$ & $10(31.25)$ & $50(7.41)$ \\
$\begin{array}{l}\text { Mental health } \\
\text { Holistic health }\end{array}$ & $3(18.75)$ & $33(5.26)$ & $8(25.00)$ & $44(6.52)$ \\
$\begin{array}{l}\text { Breast health } \\
\text { Other physical health }\end{array}$ & $4(25.00)$ & $21(3.35)$ & $7(21.88)$ & $32(4.74)$ \\
Total & $/$ & $25(3.99)$ & $/$ & $25(3.70)$ \\
\hline
\end{tabular}

health, homophobia was universally experienced by gay men $(19,20)$, along with helplessness and other stressful feelings, which were also common among general homosexuals $(17,18)$. These may have further negative effects on their well-being directly or indirectly (32). Regarding social well-being, there were a certain number of investigations on the quality of life of general MSM $(89,90)$, MSMW (91), and HIV-infected MSM (92-94); and their perceived or received social support (95-99). These findings suggest that social support, which could serve as a protective factor against mental issues, should be further 
TABLE 7 | Specific health-related variables and corresponding measurements.

\begin{tabular}{|c|c|c|c|}
\hline Concept characteristics & & $\begin{array}{l}\text { No. of } \\
\text { studies }\end{array}$ & Percentage \\
\hline Specific variables $(\geq 30)$ & Health domain & & \\
\hline General sexual behavior & Sexual health & 218 & $32.30 \%$ \\
\hline HIV screening & Sexual health & 107 & $15.85 \%$ \\
\hline Condom use & Sexual health & 94 & $13.93 \%$ \\
\hline HIV testing behavior & Sexual health & 78 & $11.56 \%$ \\
\hline Syphilis screening & Sexual health & 69 & $10.22 \%$ \\
\hline Drug use & Social well-being & 65 & $9.63 \%$ \\
\hline Depression & Mental health & 64 & $9.48 \%$ \\
\hline HIV/AIDS knowledge & Sexual health & 58 & $8.59 \%$ \\
\hline HIV prevalence & Sexual health & 54 & $8.00 \%$ \\
\hline Risky behavior ${ }^{\mathrm{b}}$ & Sexual health & 44 & $6.52 \%$ \\
\hline Social support & Social well-being & 33 & $4.89 \%$ \\
\hline Syphilis prevalence & Sexual health & 31 & $4.59 \%$ \\
\hline Unprotected anal intercourse & Sexual health & 31 & $4.59 \%$ \\
\hline Anxiety & Mental health & 30 & $4.44 \%$ \\
\hline \multicolumn{4}{|c|}{ Measurements of all specific variables } \\
\hline Not mentioned & & 1399 & $60.15 \%$ \\
\hline Scales/Questionnaires ${ }^{\mathrm{a}}$ & & 453 & $19.48 \%$ \\
\hline Laboratory tests & & 340 & $14.62 \%$ \\
\hline Self-developed scales ${ }^{a}$ & & 110 & $4.73 \%$ \\
\hline Not available & & 24 & $1.03 \%$ \\
\hline \multicolumn{4}{|l|}{ Validation of measurements ${ }^{a}$} \\
\hline Yes & & 468 & $83.13 \%$ \\
\hline No & & 95 & $16.87 \%$ \\
\hline
\end{tabular}

a Validation of those measurement tools explicitly mentioned in the study. "Risky behavior" refers to different types of high-risk behavior, such as multiple sex partners, one-night stands, alcohol abuse, or other uncategorized behaviors that may cause health hazards.

enhanced. While there were no such studies targeting female sexual minorities, similar studies among this relatively unnoticed population should be conducted to investigate and improve their quality of life.

In addition, this review provided some other novel discoveries that have not yet been reported. First, the comparison of the cooperation between author institutions in $\mathrm{CN}$ and $\mathrm{EN}$ language journals showed greater international cooperation when publishing EN articles and greater domestic cooperation when publishing $\mathrm{CN}$ ones. This finding can be attributed to factors such as the language advantage and increasing international exchanges and cooperation of scholars. Second, the distribution of the profession of authors showed that the most common academic major was public health (63.7\%), followed by psychology (6.4\%), global health $(3.9 \%)$, and nursing $(2.7 \%)$. This indicates that scholars in the field of public health have relatively more experience, insights, and contributions to research on the health of sexual minorities. This finding also serves as a reminder for researchers in other disciplines to take the initiative to carry out relevant research. Third, regarding the dynamic development of sampling methods, with the increased visibility of these minority populations and the popularization of the Internet, sampling methods have gradually transitioned from using a venuebased approach to using multiple methods. Thus, more recent surveys now rely on the Internet or smartphone applications. Correspondingly, many new investigation approaches and more innovative intervention projects have been promoted, such as crowdsourcing interventions to promote HIV/STI prevention $(100,101)$ and the use of Internet popular opinion leaders (iPOL) interventions that rely on online peer support (102). This finding suggests that academics should carry out research with a developmental and more personcentered perspective to better promote health outcomes in these populations.

This review has some implications for relevant stakeholders regarding the holistic health improvement of homosexual and bisexual Chinese. First, for health service providers, especially medical staff in the field of public health, their gender, and sexuality literacy should be improved, as they are the direct providers of health care. Therefore, it is recommended that health professionals learn relevant knowledge so as to provide more diverse and professional advice. In addition, healthrelated institutions need to be as open and diversified as possible to provide more health services and increase health care accessibility, allowing more sexual minorities to actively seek help to a greater extent. Second, studies have shown that community engagement can help with health improvement by enhancing knowledge dissemination and facilitating testing (22, 103), thus highlighting the importance of a diverse and supportive community environment. Therefore, for social service providers, it is recommended that they proactively reach out to help and provide more social and psychological information to eliminate homophobia, biphobia, and other forms of discrimination. At the same time, all service providers should consciously participate in multidisciplinary cooperation to better provide person-centered holistic health care that can empower all sexual minorities to take pride in their own health and encourage them to maintain healthy behaviors. Finally, compared to studies on various general populations under the heteronormativity context, there are very few studies on sexual minorities. Thus, there is an urgent need for researchers or scholars from different disciplines to conduct research from different perspectives, with the common goal of helping everyone express their true selves and lead healthy lives.

This review has several limitations that should be addressed. First, despite the inclusion of numerous references in both languages, it is still difficult for a single review to accurately conclude the holistic health status of homosexual and bisexual Chinese from a comprehensive perspective. Due to the uneven quality of the included literature (as described in Supplementary Material 6), this review only summarized the objective demographic data (population and context information) from all the publications. While the summarization of concept information and study characteristics was based on the data extracted from EN publications only, most of which were peer-reviewed. Second, although this review attempted to conduct quality assessments of all included journals, nearly a quarter of the included articles were published in relatively low-quality journals, thereby leading 
to a potential limitation. Third, this review only included studies conducted in mainland China, Hong Kong, Macau, and Taiwan, while studies on overseas Chinese were excluded due to different social ideologies and policy backgrounds. This could mean that the findings were less representative of all homosexual and bisexual Chinese worldwide. Further comparison studies among the Chinese in various regions can be carried out in the future. Finally, this review involved a large number of references; hence, the findings might not be sufficiently population-specific or health-specific. Thus, more precise reviews or more targeted studies are needed in the future.

\section{CONCLUSIONS}

This scoping review summarized all the literature on the holistic health of homosexual and bisexual Chinese from 2001 to 2020. Existing evidence showed that previous research focused more on male than female sexual minorities, on HIV-/STI-centered surveys than person-centered investigations, on CDC-led interventions than crowdsourcing programs, and negative health conditions than positive health promotion. Thus, more investigations centered on the female population and following person-centered interventions are highly needed, along with the implementation of health promotion programs for this population group. Furthermore, projects that increase community engagement should be carried out among different communities, whether in communities based on gender or sexual orientation. Finally, researchers with more multidisciplinary backgrounds need to participate in the research on sexual minorities. In particular, there should be greater involvement of professionals from different disciplines to deliver adequate

\section{REFERENCES}

1. Tanner HM. The Offense of Hooliganism and The moral dimension of china's pursuit of modernity, 1979-1996. Twentieth-Century China. (2000) 26:1-40. doi: $10.1179 /$ tcc.2000.26.1.1

2. Chen YF. Chinese classification of mental disorders (CCMD-3): towards integration in international classification. Psychopathology. (2002) 35:171-5. doi: 10.1159/000065140

3. Yen CF, Ko NY, Huang YT, Chen MH, Lin IH, Lu WH. Preference about laws for the legal recognition of same-sex relationships in taiwanese people before and after same-sex marriage referenda: a facebook survey study. Int $J$ Environ Res Public Health. (2020) 17:2000. doi: 10.3390/ijerph17062000

4. Esteve A, Lesthaeghe R, Lopez-Gay A. The latin American cohabitation boom, 1970-2007. Popul Dev Rev. (2012) 38:55-81. doi: 10.1111/j.1728-4457.2012.00472.x

5. Zhao Y, Ma Y, Chen R, Li F, Qin X, Hu Z. Non-disclosure of sexual orientation to parents associated with sexual risk behaviors among gay and bisexual MSM in China. AIDS Behav. (2016) 20:193-203. doi: 10.1007/s10461-015-1135-6

6. Bellhouse C, Walker S, Fairley CK, Chow EP, Bilardi JE. Getting the terminology right in sexual health research: the importance of accurately classifying fuck buddies among men who have sex with men. Sex Transm Infect. (2018) 94:487-9. doi: 10.1136/sextrans-2016-053000 health care and social care services for Chinese homosexuals and bisexuals.

\section{DATA AVAILABILITY STATEMENT}

The original contributions presented in the study are included in the article/Supplementary Material, further inquiries can be directed to the corresponding author/s.

\section{AUTHOR CONTRIBUTIONS}

CW and EPHC conceptualized this review and designed the research questions. CW prepared and drafted the manuscript. CW and EPHC performed the initial screening of the articles and were involved in the development of the data extraction form. CW piloted the data extraction form and conducted the data extraction with EPHC independently. CW carried out data analysis under the guidance of EPHC. EPHC and PHC are the guarantors and have contributed to the critical revision of the manuscript. All the authors have read and approved the final manuscript.

\section{ACKNOWLEDGMENTS}

We would like to thank Ms. Kitty Wai Ying Choi for her contribution to the pilot data searching and study selection and the development of the data extraction form.

\section{SUPPLEMENTARY MATERIAL}

The Supplementary Material for this article can be found online at: https://www.frontiersin.org/articles/10.3389/fpubh. 2021.710575/full\#supplementary-material

7. Liu C. "Red is not the only color of a rainbow": the making and resistance of the "MSM" subject among gay men in China. Soc Sci Med. (2020) 252:112947. doi: 10.1016/j.socscimed.2020.112947

8. Bailey JV, Farquhar C, Owen C, Mangtani P. Sexually transmitted infections in women who have sex with women. Sex Transm Infect. (2004) 80:244-6. doi: 10.1136/sti.2003.007641

9. Liao M, Kang D, Jiang B, Tao X, Qian Y, Wang T, et al. Bisexual behavior and infection with HIV and syphilis among men who have sex with men along the east coast of China. AIDS Patient Care STDS. (2011) 25:683-91. doi: 10.1089/apc.2010.0371

10. Liao $M$, Wang $M$, Shen $X$, Huang $P$, Yang $X$, Hao L, et al. Bisexual behaviors, HIV knowledge, and stigmatizing/discriminatory attitudes among men who have sex with men. PLoS ONE. (2015) 10:e0130866. doi: 10.1371/journal.pone.0130866

11. World Health Organization. What is the WHO definition of health? (1948). Available online at: https://www.who.int/news-room/fact-sheets/ detail/mental-health-strengthening-our-response

12. Dong MJ, Peng B, Liu ZF, Ye QN, Liu H, Lu XL, et al. The prevalence of HIV among MSM in China: a large-scale systematic analysis. BMC Infect Dis. (2019) 19:1000. doi: 10.1186/s12879-019-4559-1

13. Wu ZY, Xu J, Liu EW, Mao YR, Xiao Y, Sun XH, et al. HIV and syphilis prevalence among men who have sex with men: a cross-sectional survey of 61 cities in China. Clin Infect Dis. (2013) 57:298-309. doi: 10.1093/cid/cit210 
14. Wang XF, Norris JL, Liu YJ, Reilly KH, Wang N. Health-related attitudes and risk factors for sexually transmitted infections of Chinese women who have sex with women. Chin Med J. (2012) 125:2819-25. doi: 10.3760/cma.j.issn.0366-6999.2012.16.004

15. Wang X, Norris JL, Liu Y, Vermund SH, Qian HZ, Han L, et al. Risk behaviors for reproductive tract infection in women who have sex with women in Beijing, China. PLoS ONE. (2012) 7:e40114. doi: 10.1371/journal.pone.0040114

16. Choi KH, Steward WT, Miege P, Hudes E, Gregorich SE. Sexual stigma, coping styles, and psychological distress: a longitudinal study of men who have sex with men in Beijing, China. Arch Sex Behav. (2016) 45:1483-91. doi: $10.1007 / \mathrm{s} 10508-015-0640-\mathrm{z}$

17. Ren Z, Howe CQ, Zhang W. Maintaining "mianzi" and "lizi": Understanding the reasons for formality marriages between gay men and lesbians in China. Transcult Psychiatry. (2019) 56:213-32. doi: 10.1177/1363461518799517

18. Shi $\mathrm{X}, \mathrm{Xu} \mathrm{W}$, Zheng Y. Heterosexual marital intention: effects of internalized homophobia, homosexual identity, perceived family support, and disclosure among Chinese gay and bisexual men. J Homosex. (2018) 67:452-67. doi: $10.1080 / 00918369.2018 .1547558$

19. Ren Z, Hood RW Jr. Internalized homophobia scale for gay chinese men: conceptualization, factor structure, reliability, and associations with hypothesized correlates. Am J Mens Health. (2018) 12:1297-306. doi: $10.1177 / 1557988318768603$

20. Xu W, Zheng L, Xu Y, Zheng Y. Internalized homophobia, mental health, sexual behaviors, and outness of gay/bisexual men from Southwest China. Int J Equity Health. (2017) 16:36. doi: 10.1186/s12939-017-0530-1

21. Ding C, Chen X, Wang W, Yu B, Yang H, Li X, et al. Sexual minority stigma, sexual orientation concealment, social support and depressive symptoms among men who have sex with men in China: a moderated mediation modeling analysis. AIDS Behav. (2020) 24:8-17. doi: 10.1007/s10461-019-02713-3

22. Zhu Y, Liu J, Chen Y, Zhang R, Qu B. The relation between mental health, homosexual stigma, childhood abuse, community engagement, and unprotected anal intercourse among MSM in China. Sci Rep. (2018) 8:3984. doi: 10.1038/s41598-018-22403-9

23. Liao M, Kang D, Tao X, Bouey JH, Aliyu MH, Qian Y, et al. Alcohol use, stigmatizing/discriminatory attitudes, and hiv high-risk sexual behaviors among men who have sex with men in China. BioMed Res Int. (2014) 2014:143738. doi: $10.1155 / 2014 / 143738$

24. Pyun T, Santos GM, Arreola S, Do T, Hebert P, Beck J, et al. Internalized homophobia and reduced HIV testing among men who have sex with men in China. Asia Pac J Public Health. (2014) 26:118-25. doi: 10.1177/1010539514524434

25. Su X, Zhou AN Li J, Shi LE, Huan X, Yan H, et al. Depression, loneliness, and sexual risk-taking among HIV-negative/unknown men who have sex with men in China. Arch Sex Behav. (2018) 47:1959-68. doi: 10.1007/s10508-017-1061-y

26. Liu JX, Zhong XN, Lu Z, Peng B, Zhang Y, Liang H, et al. Anxiety and depression associated with anal sexual practices among HIV-negative men who have sex with men in western China. Int J Environ Res Public Health. (2020) 17:464. doi: 10.3390/ijerph17020464

27. Hu Y, Zhong XN, Peng B, Zhang Y, Liang H, Dai JH, et al. Comparison of depression and anxiety between HIV-negative men who have sex with men and women (MSMW) and men who have sex with men only (MSMO): a cross-sectional study in Western China. BMJ Open. (2019) 9:e023498. doi: 10.1136/bmjopen-2018-023498

28. Wang PW, Ko NY, Hsiao RC, Chen MH, Lin HC, Yen CF. Suicidality among gay and bisexual men in taiwan: its relationships with sexuality and gender role characteristics, homophobic bullying victimization, and social support. Suicide Life Threat Behav. (2019) 49:466-77. doi: 10.1111/sltb.12451

29. Chen H, Li Y, Wang L, Zhang B. Causes of suicidal behaviors in men who have sex with men in China: a national questionnaire survey. BMC Public Health. (2015) 15:91. doi: 10.1186/s12889-015-1436-8

30. Mu H, Li Y, Liu L, Na J, Yu L, Bi X, et al. Prevalence and risk factors for lifetime suicide ideation, plan and attempt in Chinese men who have sex with men. BMC Psychiatry. (2016) 16:10. doi: 10.1186/s12888-016-0830-9
31. Higgins DJ. Differences between previously married and never married 'gay' men: family background, childhood experiences and current attitudes. $J$ Homosex. (2004) 48:19-41. doi: 10.1300/J082v48n01_02

32. Sun S, Pachankis JE Li X, Operario D. Addressing Minority Stress and Mental Health among Men Who Have Sex with Men (MSM) in China. Curr HIV/AIDS Rep. (2020) 17:35-62. doi: 10.1007/s11904-019-00479-w

33. Gu J, Lau JT, Wang Z, Wu AM, Tan X. Perceived empathy of service providers mediates the association between perceived discrimination and behavioral intention to take up HIV antibody testing again among men who have sex with men. PLoS ONE. (2015) 10:e0117376. doi: 10.1371 /journal.pone. 0117376

34. Choi K, Hudes ES, Steward WT. Social discrimination, concurrent sexual partnerships, and HIV risk among men who have sex with men in Shanghai, China. AIDS Behav. (2008) 12:S71-7. doi: 10.1007/s10461-008-9394-0

35. Bai X, Xu J, Yang J, Yang B, Yu M, Gao Y, et al. HIV prevalence and high-risk sexual behaviours among MSM repeat and first-time testers in China: implications for HIV prevention. J Int AIDS Soc. (2014) 17:18848. doi: 10.7448/IAS.17.1.18848

36. Bien CH, Muessig KE, Lee R, Lo EJ, Yang LG, Yang B, et al. HIV and syphilis testing preferences among men who have sex with men in South China: a qualitative analysis to inform sexual health services. PLoS ONE. (2015) 10:e0124161. doi: 10.1371/journal.pone.0124161

37. Cai WD, Zhao J, Zhao JK, Raymond HF, Feng YJ, Liu J, et al. HIV prevalence and related risk factors among male sex workers in Shenzhen, China: results from a time-location sampling survey. Sex Transm Infect. (2010) 86:15-20. doi: 10.1136/sti.2009.037440

38. Chen L, Yang J, Ma Q, Pan X. Prevalence of active syphilis infection and risk factors among HIV-positive MSM in Zhejiang, China in 2015: a cross-sectional study. Int J Environ Res Public Health. (2019) 16:1507. doi: 10.3390/ijerph16091507

39. Chen Q, Sun Y, Sun W, Hao M, Li G, Su X, et al. Trends of HIV incidence and prevalence among men who have sex with men in Beijing, China: Nine consecutive cross-sectional surveys, 2008-2016. PLoS ONE. (2018) 13:e201953. doi: 10.1371/journal.pone.0201953

40. Chen Y, Tang W, Chen L, Shi L, Liu X, Xu J, et al. Changing epidemic of HIV and syphilis among resident and migrant men who have sex with men in Jiangsu, China. Sci Rep. (2017) 7:9478. doi: 10.1038/s41598-017-08671-x

41. Chow EP, Lau JT, Zhuang X, Zhang X, Wang Y, Zhang L, et al. prevalence trends, risky behaviours, and governmental and community responses to the epidemic among men who have sex with men in China. Biomed Res Int. (2014) 2014:607261. doi: 10.1155/2014/607261

42. Chow EP, Wilson DP, Zhang L, HIV. and syphilis co-infection increasing among men who have sex with men in China: a systematic review and metaanalysis. PLoS ONE. (2011) 6:e22768. doi: 10.1371/journal.pone.0022768

43. Duan Y, Zhang H, Wang J, Wei S, Yu F, She M. Community-based peer intervention to reduce HIV risk among men who have sex with men in Sichuan province, China. Aids Educ Prev. (2013) 25:38-48. doi: 10.1521/aeap.2013.25.1.38

44. Hu X, Wang Y, LGB. identity among young Chinese: the influence of traditional culture. J Homosex. (2013) 60:667-84. doi: 10.1080/00918369.2013.773815

45. Li Y. Risk Perception, Mental health, Risk Behaviors of Homosexuals and its Media Influence Factors [Master of Philosophy]. Guangzhou: Jinan University. (2017).

46. Li H. The mental health status of homosexual people and its influencing factors. Sci Soc Psychol. (2010) 25:80-5. Avaiable online at: http://qikan.cqvip. com/Qikan/Article/Detail?id=34144610

47. Arksey H, O’Malley L. Scoping studies: towards a methodological framework. Int $J$ Soc Res Methodol. (2005) 8:19-32. doi: $10.1080 / 1364557032000119616$

48. Levac D, Colquhoun H, O'Brien KK. Scoping studies: advancing the methodology. Implement Sci. (2010) 5:69. doi: 10.1186/1748-590 8-5-69

49. Peters MD, Godfrey CM, Khalil H, McInerney P, Parker D, Soares CB. Guidance for conducting systematic scoping reviews. Int $J$ Evid Based Healthc. (2015) 13:141-6. doi: 10.1097/XEB.0000000000000050 
50. Peters M, Godfrey C, McInerney P, Munn Z, Tricco A, Khalil H. Chapter 11: Scoping Reviews (2020 version). The Joanna Briggs Institute. (2020). Available online at: https://reviewersmanual.joannabriggs.org/

51. Tricco AC, Lillie E, Zarin W, O’Brien KK, Colquhoun H, Levac D, et al. PRISMA extension for scoping reviews (PRISMA-ScR): checklist and explanation. Ann Intern Med. (2018) 169:467-73. doi: 10.7326/M18-0850

52. Wu C, Choi EPH, Chau PH, Choi KWY. The holistic health status of chinese homosexual and bisexual adults: a scoping review protocol. Jmir Res Protoc. (2021). doi: 10.2196/preprints.30870

53. Joanna Briggs Institute. Joanna Briggs Institute Reviewer's Manual. 4th Edition: The Joanna Briggs Institute. (2020). Available online at: https:// reviewersmanual.joannabriggs.org/.

54. World Health Organization. Special initiative for mental health (2019-2023): Universal Health Coverage for Mental Health. 2019.

55. Jaspal R. The Social Psychology of Gay Men. Cham: Palgrave Macmillan UK. (2019). doi: 10.1007/978-3-030-27057-5

56. Edwards WM, Coleman E. Defining sexual health: a descriptive overview. Arch Sex Behav. (2004) 33:189-95. doi: 10.1023/B:ASEB.0000026619.95734.d5

57. Giami A. Sexual health: the emergence, development, and diversity of a concept. Annu Rev Sex Res. (2002) 13:1-35.

58. World Health Organization. Definitions of Sexual Health. (2006). Available online at: https://www.who.int/health-topics/sexual-health\#tab=tab_2.

59. McGowan J, Sampson M, Salzwedel DM, Cogo E, Foerster V, Lefebvre C, et al. Peer review of electronic search strategies: 2015 guideline statement. $J$ Clin Epidemiol. (2016) 75:40-6. doi: 10.1016/j.jclinepi.2016.01.021

60. Rebecca R, Horey D, Oliver S, McKenzie J, Prictor M, Santesso N, et al. Cochrane Consumers and Communication Protocol Text and Additional Guidance for Review Authors. Melbourne: La Trobe University. (2019). Available online at: https://latrobe.figshare.com/articles/Standard_Protocol_ Text_and_Additional_Guidance_for_Review_Authors/6692969.

61. Borgatti SP, Everett MG, Freeman LC. UCINET VI for windows: software for social network analysis. (2002).

62. Borgatti SP. NetDraw Software for Network Visualization. Lexington, KY: Analytic Technologies. (2002).

63. Moher D, Liberati A, Tetzlaff J, Altman DG. Preferred reporting items for systematic reviews and meta-analyses: the PRISMA statement. J Clin Epidemiol. (2009) 62:1006-12. doi: 10.1016/j.jclinepi.2009. 06.005

64. Tang S, Tang W, Meyers K, Chan P, Chen Z, Tucker JD, et al. Epidemiology and responses among men who have sex with men and transgender individuals in China: a scoping review. BMC Infect Dis. (2016) 16:588. doi: 10.1186/s12879-016-1904-5

65. Hou C-N, Lu H-Y. Online networks as a venue for social support: a qualitative study of married bisexual men in Taiwan. J Homosex. (2013) 60:1280-96. doi: 10.1080/00918369.2013.806170

66. Li Y, Johnson BD, Jenkins-Guarnieri MA. Sexual identity development and subjective well-being among Chinese lesbians. Int Perspect Psychol Res Prac Consultation. (2013) 2:242-54. doi: 10.1037/a0033752

67. Lin K. Study on the Current Situation and Countermeasure of STD/AIDS Related Health Intervention of Homosexual Website in China. Shanghai: Fudan University. (2008).

68. Liu PL, Yeo TED. Breast health, risk factors, and cancer screening among lesbian, bisexual, and queer/questioning women in China. Health Care Women Int. (2019) 40:1-15. doi: 10.1080/07399332.2019.1 571062

69. Wang Y-C, Griffiths J, Grande G. Factors associated with Taiwanese lesbians' breast health-care behavior and intentions: qualitative interview findings. Women Health. (2017) 57:962-75. doi: 10.1080/03630242.2016.12 22331

70. Wang Y-C, Griffiths J, Grande G. The influence of gender identities on body image and breast health among sexual minority women in Taiwan: implications for healthcare practices. Sex Roles J Res. (2018) 78:242-54. doi: 10.1007/s11199-017-0793-4

71. Wang YC, Chang SR, Miao NF. The role of butch versus femme identity in body image and breast health among lesbians in taiwan: results of an online survey. J Nurs Sch. (2020) 52:174-82. doi: 10.1111/jnu.12544
72. Wei C, Liu W. Coming out in Mainland China: a national survey of LGBTQ students. J LGBT Youth. (2019) 16:192-219. doi: 10.1080/19361653.2019.1565795

73. Mak WWS, Ng AC, Mo PKH, Chong ESK. Coming out among lesbians, gays, and bisexual individuals in Hong Kong: application of the theory of planned behavior and the moderating role of attitudinal ambivalence. Sex Role J Res. (2010) 63:189-200. doi: 10.1007/s11199-010-9778-2

74. Meng X, Zou H, Beck J, Xu Y, Zhang X, Miao X, et al. Trends in HIV prevalence among men who have sex with men in China 200309: a systematic review and meta-analysis. Sex Health. (2013) 10:211-9. doi: 10.1071/SH12093

75. Wang X, Lan G, Shen Z, Vermund SH, Zhu Q, Chen Y, et al. HIV and syphilis prevalence trends among men who have sex with men in Guangxi, China: yearly cross-sectional surveys, 2008-2012. BMC Infec Dis. (2014) 14:367. doi: 10.1186/1471-2334-14-367

76. Wei S, Zhang H, Wang J, Song D, Duan Y, Yu F, et al. HIV and syphilis prevalence and associated factors among young men who have sex with men in 4 cities in China. AIDS Behav. (2013) 17:1151-8. doi: 10.1007/s10461-011-0110-0

77. Yang X. Prevalence and factors of antiretroviral therapy usage among HIV-positive men who have sex with men under a new treatment policy in China [Ph.D.]. Ann Arbor: The Chinese University of Hong Kong (Hong Kong) (2018).

78. Zhou W, Zhao M, Wang X, Schilling RF, Zhou S, Qiu HY, et al. Treatment adherence and health outcomes in MSM with HIV/AIDS: patients enrolled in "one-stop" and standard care clinics in Wuhan China. PLoS ONE. (2014) 9:e113736. doi: 10.1371/journal.pone.0113736

79. Qu D, Zhong X, Xiao G, Dai J, Liang H, Huang A. Adherence to pre-exposure prophylaxis among men who have sex with men: a prospective cohort study. Int J Infect Dis. (2018) 75:52-9. doi: 10.1016/j.ijid.2018.08.006

80. Hu Y. Zhong X-n, Peng B, Zhang Y, Liang H, Dai J-h, et al. Associations between perceived barriers and benefits of using HIV pre-exposure prophylaxis and medication adherence among men who have sex with men in Western China. BMC Infect Dis. (2018) 18:1-8. doi: 10.1186/s12879-018-3497-7

81. Ye S, Xiao Y, Jin C, Cassell H, Blevins M, Sun J, et al. Effectiveness of integrated HIV prevention interventions among Chinese men who have sex with men: evaluation of a 16-city public health program. PLOS ONE. (2012) 7:e50873. doi: 10.1371/journal.pone.0050873

82. Zheng L, Zheng Y. Efficacy of human immunodeficiency virus prevention interventions among men who have sex with men in China: a meta-analysis. Sex Transm Dis. (2012) 39:886-93. doi: 10.1097/OLQ.0b013e31826ae85e

83. Ren XL, Wu ZY Mi GD, McGoogan J, Rou KM, Zhao Y. Uptake of HIV self-testing among men who have sex with men in Beijing, China: a cross-sectional study. Biomed Environ Sci. (2017) 30:407-17. doi: 10.1186/s40249-017-0326-y

84. Zhu X, Zhang W, Operario D, Zhao Y, Shi A, Zhang Z, et al. Effects of a mobile health intervention to promote HIV self-testing with MSM in China: a randomized controlled trial. AIDS Behav. (2019) 23:3129-39. doi: 10.1007/s10461-019-02452-5

85. Wong HT. Hoo, Tam HY, Chan DP, Chung, Lee SS. Usage and acceptability of HIV self-testing in men who have sex with men in Hong Kong. AIDS Behav. (2015) 19:505-15. doi: 10.1007/s10461-014-0881-1

86. Zheng L, Zheng Y. Sexual satisfaction in Chinese gay and bisexual men: relationship to negative sexual minority identity and sexual role preference. Sex Relationship Ther. (2017) 32:75-88. doi: 10.1080/14681994.2016.1200027

87. Chen G, Cao Y, Yao Y, Li M, Tang W, Li J, et al. Syphilis incidence among men who have sex with men in China: results from a metaanalysis. Int J STD AIDS. (2017) 28:170-8. doi: 10.1177/0956462416 638224

88. Yang LG, Zhang XH, Zhao PZ, Chen ZY, Ke WJ, Ren XQ, et al. Gonorrhea and chlamydia prevalence in different anatomical sites among men who have sex with men: a cross-sectional study in Guangzhou, China. BMC Infect Dis. (2018) 18:675. doi: 10.1186/s12879-018-3579-6

89. Liu J, Qu B, Zhu Y, Hu B. The influence of social support on quality of life of men who have sex with men in China: a preliminary study. PLOS ONE. (2015) 10:e0127644. doi: 10.1371/journal.pone.0127644 
90. Yaxin Z, Jie L, Bo Q, Bingxue H, Yang Z, Zhu Y, et al. Relationship between quality of life and unprotected anal intercourse among Chinese men who have sex with men: a cross-sectional study. BMC Public Health. (2016) 16:1-6. doi: 10.1186/s12889-016-3076-Z

91. Chen JP, Han MM, Liao ZJ Dai ZZ, Liu L, Chen H, et al. HIVrelated behaviors, social support and health-related quality of life among men who have sex with men and women (MSMW): a crosssectional study in Chongqing, China. PLoS One. (2015) 10:e0118651. doi: 10.1371/journal.pone.0118651

92. Song B, Yan C, Lin Y, Wang F, Wang L. Health-related quality of life in HIVinfected men who have sex with men in China: a cross-sectional study. Med Sci Monit. (2016) 22:2859-70. doi: 10.12659/MSM.897017

93. Zhang P, Gao J, Wang Y, Sun Q, Sun X. Effect of chronic disease selfmanagement program on the quality of life of HIV-infected men who have sex with men: an empirical study in Shanghai, China. Int J Health Plann Manage. (2019) 34:1055-64. doi: 10.1002/hpm.2874

94. Shao B, Song B, Feng S, Lin Y, Du J, Shao H, et al. The relationship of social support, mental health, and health-related quality of life in human immunodeficiency virus-positive men who have sex with men: From the analysis of canonical correlation and structural equation model: a cross-sectional study. Medicine (Baltimore). (2018) 97:e11652. doi: 10.1097/MD.0000000000011652

95. Du M, Zhao J, Zhang J, Lau JTF, Mo PKH Li J. Depression and social support mediate the effect of HIV self-stigma on condom use intentions among Chinese HIV-infected men who have sex with men. AIDS Care. (2018) 30:1197-206. doi: 10.1080/09540121.2018.1487916

96. Li J, Mo PK, Wu AM, Lau JT. Roles of self-stigma, social support, and positive and negative affects as determinants of depressive symptoms among HIV infected men who have sex with men in China. AIDS Behav. (2017) 21:261-73. doi: 10.1007/s10461-016-1321-1

97. Mo PKH, Chen X, Lam EHK Li J, Kahler CW, Lau JTF. The moderating role of social support on the relationship between anxiety, stigma, and intention to use illicit drugs among HIV-positive men who have sex with men. AIDS Behav. (2020) 24:55-64. doi: 10.1007/s10461-019-02719-X

98. Yan H, Li X, Li J, Wang W, Yang Y, Yao X, et al. Association between perceived HIV stigma, social support, resilience, self-esteem, and depressive symptoms among HIV-positive men who have sex with men (MSM) in Nanjing, China. AIDS Care. (2019) 31:1069-76. doi: 10.1080/09540121.2019.1601677
99. Wang C-C, Lin H, Chen M-H, Ko N-Y, Chang Y-P, Lin IM, et al. Effects of traditional and cyber homophobic bullying in childhood on depression, anxiety, and physical pain in emerging adulthood and the moderating effects of social support among gay and bisexual men in Taiwan. Neuropsychiatr Dis Treat. (2018) 14:9. doi: 10.2147/NDT.S164579

100. Tang W, Han L, Best J, Zhang Y, Mollan K, Kim J, et al. Crowdsourcing HIV test promotion videos: a noninferiority randomized controlled trial in China. Clinical Infect Dis. (2016) 62:1436-42. doi: 10.1093/cid/ciw171

101. Tang W, Wei C, Cao B, Wu D, Li KT, Lu H, et al. Crowdsourcing to expand HIV testing among men who have sex with men in China: a closed cohort stepped wedge cluster randomized controlled trial. PLoS Med. (2018) 15:e1002645. doi: 10.1371/journal.pmed.1002645

102. Ko N-Y, Hsieh C-H, Wang M-C, Lee C, Chen C-L, Chung A-C, et al. Effects of internet popular opinion leaders (iPOL) among internet-using men who have sex with men. J Med Internet Res. (2013) 15:e40. doi: 10.2196/jmir. 2264

103. Zhang TP, Liu C, Han L, Tang W, Mao J, Wong T, et al. Community engagement in sexual health and uptake of HIV testing and syphilis testing among MSM in China: a cross-sectional online survey. J Int AIDS Soc. (2017) 20:21372. doi: 10.7448/IAS.20.01/21372

Conflict of Interest: The authors declare that the research was conducted in the absence of any commercial or financial relationships that could be construed as a potential conflict of interest.

Publisher's Note: All claims expressed in this article are solely those of the authors and do not necessarily represent those of their affiliated organizations, or those of the publisher, the editors and the reviewers. Any product that may be evaluated in this article, or claim that may be made by its manufacturer, is not guaranteed or endorsed by the publisher.

Copyright (c) $2021 \mathrm{Wu}$, Choi and Chau. This is an open-access article distributed under the terms of the Creative Commons Attribution License (CC BY). The use, distribution or reproduction in other forums is permitted, provided the original author(s) and the copyright owner(s) are credited and that the original publication in this journal is cited, in accordance with accepted academic practice. No use, distribution or reproduction is permitted which does not comply with these terms. 